\title{
A New Numerical Modelling Method for System Energy Efficiency Calculation
}

\author{
Xin Song ${ }^{1}$, Chengqing Yuan ${ }^{1}$, Yan Zhang ${ }^{1}$, Qing $\mathrm{Li}^{2}$, Zhixiong $\mathrm{Li}^{3}$ \\ ${ }^{1}$ Reliability Engineering Institute, School of Energy and Power Engineering, \\ Wuhan University of Technology, \\ Wuhan 430063, P.R. China \\ ${ }^{2}$ China Waterborne Transport Research Institute, \\ Beijing 100015, P.R. China \\ ${ }^{3}$ School of Mechanical, Materials, Mechatronic and Biomedical Engineering, \\ University of Wollongong, \\ Wollongong, NSW 2522, Australia \\ 452362281@qq.com
}

\begin{abstract}
This paper focuses on greenhouse gas emissions of new energy ships by investigating energy efficiency of the ships using solar photovoltaic system. According to the operating characteristics of the diesel generator set, a novel energy efficiency model of the generator diesel engine was established, where the solar photovoltaic system was included to analyze the model energy efficiency. In order to evaluate the feasibility and availability of the proposed model, experimental data acquired from the solar photovoltaic system testing, in a real-world large ro-ro ship, was collected and compared with the model output. The fuel consumption with and without the use of the solar photovoltaic system was used to analyze the ship's energy efficiency. The comparison results demonstrate that the proposed energy efficiency model for marine generator diesel engines with solar photovoltaic system is able to represent the ship's efficiency level, with an estimation error of $3.43 \%$.
\end{abstract}

Index Terms-Photovoltaic system; Fuel consumption; Engine efficiency of marine generator diesel engine; Energy efficiency model.

\section{INTRODUCTION}

With the rapid development of social economy, the economy continues to grow. At the same time, it also brings a series of problems, especially in the context of an energy crisis and environmental pollution [1]. British Petroleum (BP) released the sixty-fourth world energy statistics yearbook on June 10, 2015. The statistics show that renewable energy consumption continues to grow and the renewable energy available for exploitation is still insufficient [2]. The shipbuilding industry has brought great economic benefits and caused serious pollution [3]. Pollution from the shipbuilding industry has accounted for $7 \%$ of global pollution. Harmful gases caused by ship emissions pollution of marine environment pollution accounted for $33 \%$ [4].

Manuscript received 14 April, 2018; accepted 19 October, 2018.

This research was supported by Research Project of Advanced Technology Ship (No: MIIT[2012]540) and Innovation Groups Project of Hubei Province Natural Science Foundation (No:2013CFA007).
The international community attaches great importance to marine pollution. The International Maritime Organization (IMO) has begun to study ship $\mathrm{CO}_{2}$ emissions. The international ship anti-pollution Convention (MARPOL) states parties to the Convention early in the 1997. The IMO has been studying the relevant content. The International Maritime Organization (IMO) and the Marine Environment Protection Committee (MEPC) held the 62nd session on July 15, 2011. Based on "the protocol of 1978 revised 1973 international prevent caused by ship pollution convention" Annex VI amendments, they determined the "new ship energy efficiency design index (EEDI)" and "ship energy efficiency management plan (SEEMP)" energy efficiency standards [5], [6]. According to the standard, it requires that the new ship energy efficiency is increased by $10 \%$ from 2015 to 2019 and achieves the same growth rate every 5 years. For a relatively large number of ships, the IMO used the EEOI index method to evaluate the level of operating efficiency in 2009 [7]. The index reflects the $\mathrm{CO}_{2}$ emissions of ships in operation. Improving the energy efficiency of the ship can reduce the emission of $\mathrm{CO}_{2}$ and environmental pollution.

Researchers [8]-[11] in various countries have done significant research on reducing the emission of $\mathrm{CO}_{2}$. Through the calculation and analysis, Sun [12] et al. found that the navigation environment can significantly affect the energy efficiency of inland ships. Chang [13] found that the best deceleration is a dynamic process and mainly depends on charter rates and fuel prices. By applying a profit maximizing equation to estimate the economic efficiency of the specific route, James [14] found that the reduction of $\mathrm{CO}_{2}$ emissions and the costs of the ship can be reduced by reducing the speed of the ship. Haakon [15] conducted a survey on the emissions and costs of time fleet and found that there was great potential for reducing $\mathrm{CO}_{2}$ emissions in transport, which could be reduced by $19 \%$. These studies have contributed to reducing $\mathrm{CO}_{2}$ emissions and environmental protection.

In order to protect the ecological environment and reduce 
nonrenewable energy consumption, research and development of clean and reproducible energy must be increased [16]. In new and renewable energy, solar energy has a wide distribution, convenient use, no pollution, and is inexhaustible [17]-[19]. It is becoming the focus of research in the world. Solar photovoltaic technology has become the fastest growing new clean energy technology in the field of renewable energy, relay wind power and hydropower [20]. Because it produces no emission, no noise pollution and does not affect the ecological environment in the process of generating electricity. The application of solar energy in ships has become the most important way to solve the problem of energy consumption with the inevitable trend of the development of energy conservation and emission reduction in the shipping industry [21].

Because the application of the photovoltaic system in ships is still in the development stage [22], [23], in general, the evaluation of the energy saving effect for the solar energy is estimated by the product of the estimated specific fuel consumption and power saving. Since the specific fuel consumption is dynamic, the estimation is not accurate enough. In this paper, the model of the solar photovoltaic system based on real ship installation is studied by considering the dynamic change of specific fuel consumption. According to the working principle of the diesel generating set, the model is established from the mechanism, and the model is verified by the data of the real ship. The model can reflect the change of energy efficiency more accurately, and make a scientific and accurate assessment of the energy saving effect. Thus, the effect of reducing the $\mathrm{CO}_{2}$ emission of ships to protect the environment is achieved.

\section{TOOLS OF EVALUATING THE OPERATION ENERGY EFFICIENCY}

For the installation of the photovoltaic system modification ship, the energy efficiency operational indicator is still used [24]. This is because the IMO does not specifically introduce a new method to evaluate the operation energy efficiency. The energy efficiency operational indicator method is established to estimate the emissions of greenhouse gas emissions by means of emission factors [25]. The energy efficiency operational indicator is proportional to the emission of greenhouse gas and inversely proportional to the operation energy efficiency of the ship. The expression for the energy efficiency operational indicator of the particular voyage is

$$
I_{\text {EEOI }}=\frac{\sum_{J} F_{J} \times C_{J}}{m \times D},
$$

where $J$ is the fuel type, $F_{J}$ is the total amount of fuel consumed during the voyage, $C_{J}$ is the carbon content in fuels of types $J, m$ is the mass of cargo or passenger number in the ship according to the type of ship and $D$ is the actual distance of the transport operation.

Since the marine main engine is the main fuel consumption equipment, the large ro-ro ship will affect the proper ship main engine fuel consumption after the installation of the photovoltaic system. The large ro-ro ship will lead to changes in the resistance of the ship navigation with the installed photovoltaic system. The added resistance is divided into two parts. The first part of the resistance is due to change in the total weight of the ship, which is affected by the photovoltaic system. The change of the total weight of the ship leads to the increase of the resistance of the ship. The second part of the resistance is due to the change of air resistance, which is affected by the solar panels installed on the top deck. With the increase of resistance, the marine diesel engine consumes more fuel in the premise of the original speed.

However, the weight of the photovoltaic system, which is lighter than the total weight of the ship, can be neglected. Increased air resistance due to increasing the area of the wind is negligible. The photovoltaic system on large ro-ro ships is not used for providing ship power requirements, but for providing daily electricity demand. Thus, this paper does not consider the influence of the installation and use of the photovoltaic system on the fuel consumption of the ship's main engine.

The fuel consumption of the marine generator diesel engine is a large part of the ship's fuel consumption, which is only inferior to the marine main engine. Because the photovoltaic system provides the daily electricity demand, the use of the photovoltaic system will directly affect the fuel consumption of the marine generator diesel engine. For the large ro-ro ship, which has an installed photovoltaic system, this paper only considers the change of fuel consumption in marine generator diesel engine. According to the above formula, the energy efficiency operational indicator of marine generator diesel engine is proposed as follows

$$
I=\frac{F_{\mathrm{ae}} \times C_{\mathrm{ae}}}{m \times D}=\frac{C_{\mathrm{ae}}}{m} \int \frac{F_{\mathrm{ae}}}{V T} d T=\frac{C_{\mathrm{ae}}}{m} \int \frac{f_{\mathrm{ae}}}{V} d T,
$$

where $I$ is the energy efficiency operational indicator of marine generator diesel engine, ae is the fuel type of the marine generator diesel engine, $F_{a e}$ is the fuel consumption of the marine generator diesel engine (the unit is $\mathrm{kg}$ ), $C_{a e}$ is the carbon content in fuels of type $a e, D$ is the distance of the transport operation using the photovoltaic system, the unit is mile, $f_{a e}$ is the fuel consumption of the marine generator diesel engine in unit time (the unit is $\mathrm{kg} / \mathrm{h}$ ), $T$ is the time of the transport operation using the photovoltaic system (the unit is h), $V$ is the speed of the transport operation using the photovoltaic system (the unit is knot) and $m$ is the vehicle number of the transport operation.

For the large ro-ro ship, which was fitted with a photovoltaic system, the type of fuel, the carrying capacity and the transportation distance of the goods are relatively unchanged before and after using the photovoltaic system. However, the use of the photovoltaic system will change the fuel consumption of the ship. Therefore, the influence of the photovoltaic system on the energy efficiency operational indicator of the ship can be reflected by the influence of the photovoltaic system on the fuel consumption of marine generator diesel engine. 


\section{ENERGY EFFICIENCY MODEL OF GENERATOR DIESEL ENGINE}

Large scale ship photovoltaic systems are different from terrestrial photovoltaic systems. This is because the ship power system is a mobile and independent grid platform, which is not as infinite as the grid of the land. According to the inherent characteristics of ships, a large marine photovoltaic system is established based on fully considering the system reliability, electromagnetic compatibility and using efficiency of energy factors. The large marine photovoltaic system is divided into an off-grid power generation mode and a grid connected power generation mode. The specific system structure is shown in Fig. 1.

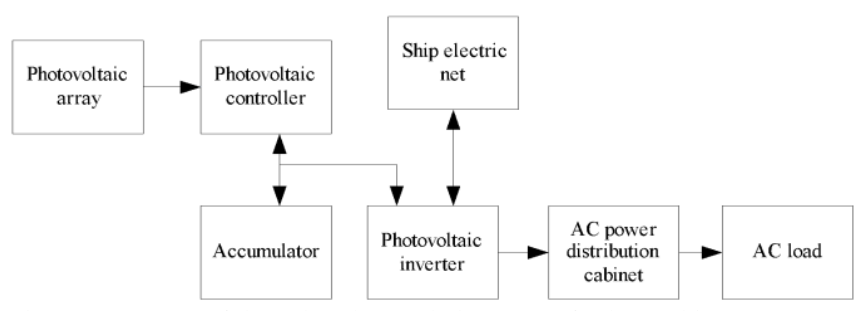

Fig. 1. Structure of the solar photovoltaic system for large ships.

When the marine diesel engine generator set is working, the heat energy is converted into mechanical energy by the diesel engine combustion of the diesel engine generating set, and the mechanical energy drives the generator to produce electricity with a cutting magnetic induction line. Generally speaking, the power of the diesel engine is related to the power of the generator

$$
P_{\text {electric }}=\left(P_{a e} \times \eta_{1}-P_{0}\right) \times \eta_{0}
$$

where $P_{\text {electric }}$ is the power of the generator (the unit is $\mathrm{kW}$ ), $P_{a e}$ is the power of the diesel engine (the unit is $\mathrm{kW}$ ), $\eta_{I}$ is the correctional power coefficient, $P_{0}$ is peripheral accessory power loss (the unit is $\mathrm{kW}$ ) and $\eta_{0}$ is the total efficiency, including generator efficiency and turbocharger efficiency.

Fuel consumption per unit time is shown in (4)

$$
f_{a e}=P_{a e} \times g_{e} \times 10^{-3},
$$

where $g_{e}$ is specific fuel consumption (the unit is $\mathrm{g} / \mathrm{kWh}$ ).

The relationship between PV system power and the total load power is shown in (5)

$$
P_{\text {sum }}=P_{\text {solar }}+P_{\text {electric }},
$$

where $P_{\text {sum }}$ is the total load power (the unit is $\mathrm{kW}$ ) and $P_{\text {solar }}$ is the power of photovoltaic system (the unit is $\mathrm{kW}$ ).

The unit time fuel consumption can be acquired using (6)

$$
f_{a e}=\frac{\frac{P_{\text {sum }}-P_{\text {solar }}}{\eta_{0}}+P_{0}}{\eta_{1}} \times g_{e} \times 10^{-3} \text {. }
$$

$I$ can be differentiated to obtain the energy efficiency of generator diesel engine $I$ by

$$
i=d I=\frac{\frac{P_{\text {sum }}-P_{\text {solar }}}{\eta_{0}}+P_{0}}{m \times v \times \eta_{1}} \times g_{e} \times C_{a e} \times 10^{-6} .
$$

The energy efficiency model of the generator diesel engine was established, based on the MATALAB/Simulink simulation platform. The model is shown in Fig. 2.

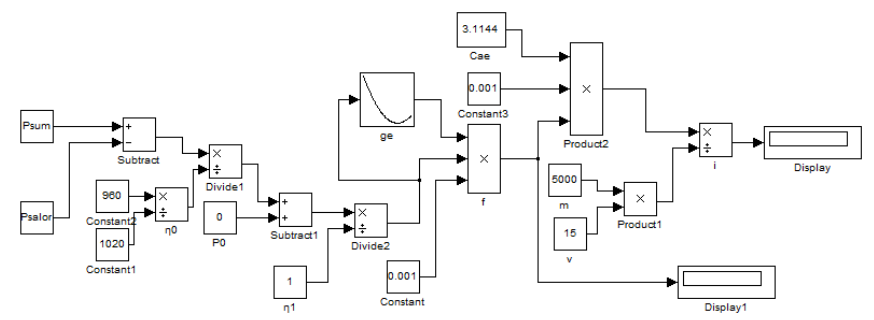

Fig. 2. Energy efficiency model of generator diesel engine.

The power of the generator diesel engine simulated the change of oil consumption with the change of PV penetration under $300 \mathrm{~kW}, 600 \mathrm{~kW}$ and $900 \mathrm{~kW}$ conditions. The photovoltaic penetration increased from $0 \mathrm{~kW}$ to the maximum power of $140 \mathrm{~kW}$. The relationship between the oil consumption and the PV penetration is shown in Fig. 3.

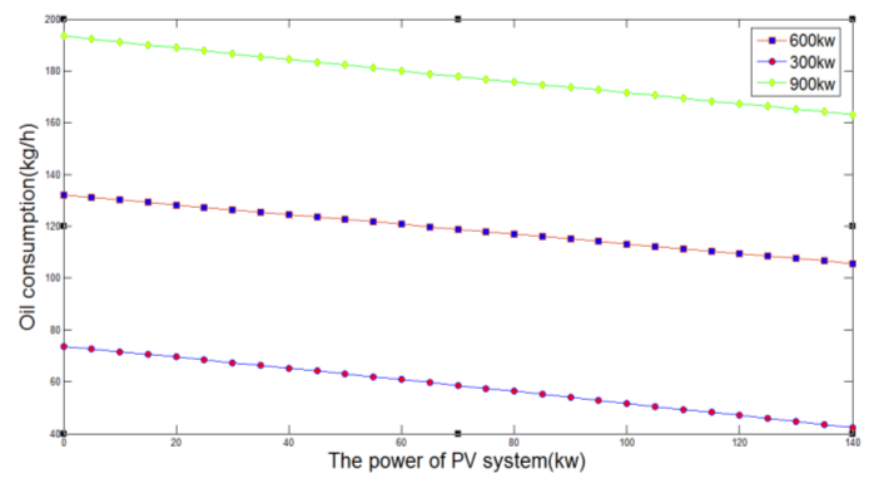

Fig. 3. Simulation value of oil consumption under different generator power and PV penetration.

As we can see in the Fig. 3, the oil consumption is different under different generator power. When the generator power is $600 \mathrm{~kW}$, the oil consumption is more than at a generator power of $300 \mathrm{~kW}$, and less than at a generator power of $900 \mathrm{~kW}$. Whether the generator is in the $300 \mathrm{~kW}, 600 \mathrm{~kW}$, or $900 \mathrm{~kW}$ - with the increase of the PV penetration - oil consumption is gradually reduced.

\section{CASE Study}

A representative large ro-ro ship in Fig. 4 is taken for our case study and is characterized by Table I.

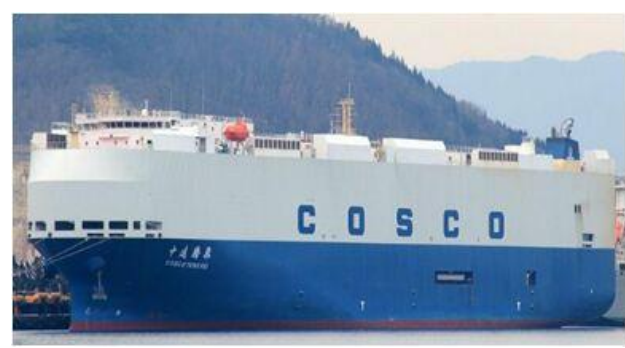

Fig. 4. The experimental large ro-ro ship. 
TABLE I. THE SPECIFIC PARAMETERS OF LARGE RO-RO SHIP.

\begin{tabular}{|c|c|c|}
\hline Parameter & $\begin{array}{c}\text { Numerical value and } \\
\text { mode }\end{array}$ & Unit \\
\hline Length overall & 182.80 & $\mathrm{~m}$ \\
\hline Depth & 14.95 & $\mathrm{~m}$ \\
\hline Design draft & 8.40 & $\mathrm{~m}$ \\
\hline Structure draft & 9.40 & $\mathrm{~m}$ \\
\hline Speed & 20.20 & $\mathrm{kn}$ \\
\hline $\begin{array}{c}\text { Total deadweight } \\
\text { tonnage }\end{array}$ & 14759.06 & $\mathrm{t}$ \\
\hline $\begin{array}{c}\text { Number of parking } \\
\text { Spaces }\end{array}$ & 5000 & $\mathrm{pctc}$ \\
\hline Generator diesel engine & HTC506-85R/2 & \\
\hline Power & 1020 & $\mathrm{~kW}$ \\
\hline
\end{tabular}

A comparison of the measured data and the calculation results of the model were needed in order to verify the accuracy of the model. According to (7), the data needed includes the power of the generation diesel engine, fuel consumption per hour, the power of the photovoltaic system, etc. The instruments and measuring units used are described in Table II, and the method of installation for fuel measurement in Fig. 5.

TABLE II. DATA ACQUISITION TOOLS.
\begin{tabular}{|c|c|c|}
\hline Data & Measuring instrument & Unit \\
\hline Time & Master clock & $\mathrm{h}$ \\
\hline Generator power & Power meter & $\mathrm{kW}$ \\
\hline $\begin{array}{c}\text { Photovoltaic system } \\
\text { power }\end{array}$ & Power analyzer & $\mathrm{kW}$ \\
\hline Load & Onboard record & $\mathrm{car}$ \\
\hline Voyage speed & DGPS & $\mathrm{kn}$ \\
\hline Oil consumption & Fuel consumption meter & $\mathrm{kg} / \mathrm{h}$ \\
\hline
\end{tabular}

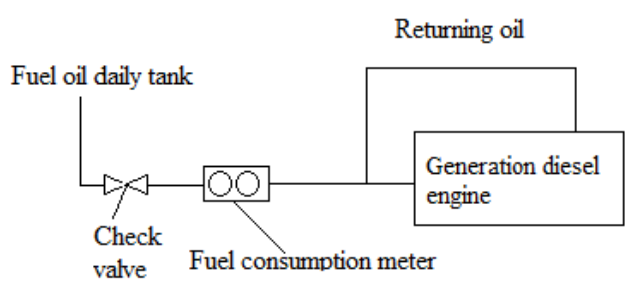

Fig. 5. Fuel consumption instrument installation diagram.

The test is divided into 6 conditions and our data are measured for 15 minutes in each condition. One power supply mode is that we use the generator diesel engine supply electric power separately and the power of generator is $625.4 \mathrm{~kW}$. The others used the generator diesel engine and the photovoltaic system to supply electric power corporately. The first condition exists with generator power at 625.4 and photovoltaic system power at 0 . The second condition exists with generator power at 643.6 and photovoltaic system power at 18 . The third condition exists with generator power at 597.0 and photovoltaic system power at 37. The fourth condition exists with generator power at 589.8 and photovoltaic system power at 50 . The fifth condition exists with generator power at 550.0 and photovoltaic system power at 80 . The sixth condition exists with generator power at 527.7 and photovoltaic system power at 120 . The data we measured is shown in Table III.

The specific fuel consumption was calculated under the above six conditions according to the model, and were compared with the measured value as shown in Fig. 6.

The change law between measured values and simulation values is consistent according to Fig. 6. The oil consumption initially increases, and then decreases gradually. The reason for the increase of oil consumption is that the power of the generator increases, despite the use of photovoltaic system power. The reason for the decrease in oil consumption is that photovoltaic power is used to reduce the generator power.

\section{TABLE III. FUEL CONSUMPTION UNDER DIFFERENT} CONDITIONS.

\begin{tabular}{|c|c|c|c|}
\hline $\begin{array}{c}\text { Measured } \\
\text { Time } \\
\text { (hh: } \mathbf{~ m m})\end{array}$ & $\begin{array}{c}\text { Generator } \\
\text { power } \\
(\mathbf{k W})\end{array}$ & $\begin{array}{c}\text { Photovoltaic } \\
\text { system power } \\
(\mathbf{k W})\end{array}$ & $\begin{array}{c}\text { Oil } \\
\text { consumption } \\
(\mathbf{k g} / \mathbf{h})\end{array}$ \\
\hline $15: 40$ & 625.4 & 0 & 132.9 \\
\hline $15: 55$ & 643.6 & 18 & 135.5 \\
\hline $16: 10$ & 597.0 & 37 & 128.0 \\
\hline $16: 25$ & 589.8 & 50 & 126.5 \\
\hline $16: 40$ & 550.0 & 80 & 119.2 \\
\hline $16: 55$ & 527.7 & 120 & 115.7 \\
\hline
\end{tabular}

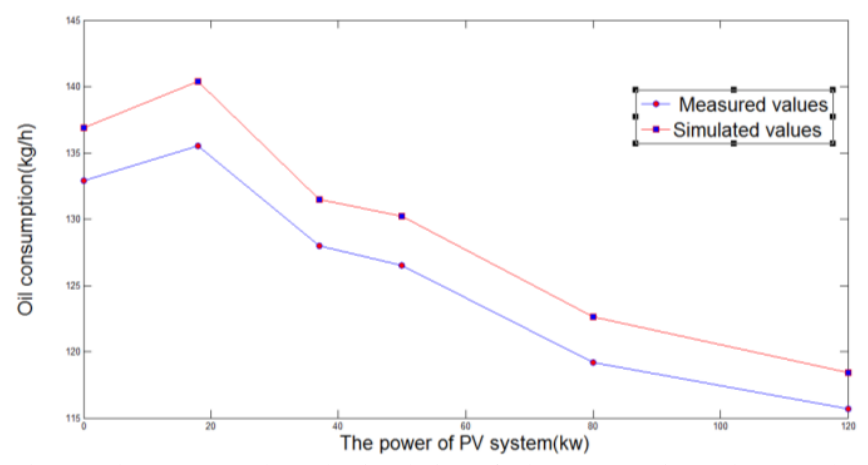

Fig. 6. The measured and simulation fuel consumption chart under different conditions.

By comparing the EEOI obtained from the simulation and calculation of the energy efficiency model with the measured data, the accuracy of the model as shown in Table IV is verified. It can be seen from Table IV that the model is highly accurate.

TABLE IV. ACCURACY OF ENERGY EFFICIENCY MODEL FOR GENERATOR DIESEL ENGINE.

\begin{tabular}{|c|c|c|c|c|}
\hline $\begin{array}{c}\text { Generator } \\
\text { power } \\
(\mathbf{k W})\end{array}$ & $\begin{array}{c}\text { Photovoltaic } \\
\text { system } \\
\text { power }(\mathbf{k W})\end{array}$ & $\begin{array}{c}\text { Measured } \\
\text { EEOI }\left(\mathbf{1 0}^{-6}\right)\end{array}$ & $\begin{array}{c}\text { Simulation } \\
\text { value of } \\
\text { EEOI }\left(\mathbf{1 0}^{-6}\right)\end{array}$ & $\begin{array}{c}\text { Relative } \\
\text { error } \\
(\boldsymbol{\%})\end{array}$ \\
\hline 625.4 & 0 & 5.52 & 5.69 & 2.99 \\
\hline 643.6 & 18 & 5.63 & 5.83 & 3.43 \\
\hline 597.0 & 37 & 5.32 & 5.46 & 2.56 \\
\hline 589.8 & 50 & 5.25 & 5.41 & 2.96 \\
\hline 550.0 & 80 & 4.95 & 5.09 & 2.75 \\
\hline 527.7 & 120 & 4.80 & 4.92 & 2.44 \\
\hline
\end{tabular}

The table can effectively evaluate and predict the energy efficiency level of the generator diesel engine when using the photovoltaic system. The reason of error is as follows: firstly, the instrument itself has a certain error; secondly, there is room for human error in the measurement process; lastly, there is potential for error between the specific fuel consumption and specific fuel consumption of bench test, because of the abrasion to the diesel generator set.

\section{CONCLUSIONS}

Green ships as a global research topic has attracted the attention of the shipping industry. Countries also put more human and material resources into the green ships, so as to effectively achieve the goal of energy conservation and emission reduction in the shipping industry. With the 
continuous development of science and technology, the application of solar energy, wind energy and other new energy on ships has a unique advantage in energy conservation and emission reduction. There are many applications of new energy sources in the global shipbuilding industry, but there are still many problems worth studying in terms of the operation process.

In this paper, ship energy efficiency and greenhouse gas emissions based on the photovoltaic system on large ro-ro ships were studied. The influence of the photovoltaic system on ship energy efficiency was also analysed. The diesel generator energy efficiency model by simulation tool was established, as well as that the relative error range is less than $3.43 \%$. According to the actual measured values that the model can accurately evaluate the energy efficiency of electric diesel engines when using the photovoltaic system was verified.

However, the developed energy efficiency model in this study needs further investigation. Since many factors, such as solar illumination time, radiation intensity and photovoltaic array temperature, etc. will affect the power of the photovoltaic system, future research can bring these factors into the model. The corresponding outcome will be reported in due course.

\section{REFERENCES}

[1] Z. Li, Y. Jiang, Q. Guo, C. Hu, Z Peng, "Multi-dimensional variational mode decomposition for bearing-crack detection in wind turbines with large driving-speed variations", Renewable Energy, vol. 116, pp. 55-73, 2018. DOI: 10.1016/j.renene.2016.12.013.

[2] British Petroleum Corporation, "Statistical review of world energy", June 2015, London. [Online]. Available: https://www.bp.com/en/global/corporate/media/speeches/bpstatistical-review-of-world-energy-2015.html

[3] H. N. Psaraftis, C. A. Kontovas, "Speed models for energy-efficient maritime transportation: a taxonomy and survey", Transportation Research Part C: Emerging Technologies, vol. 26, pp. 331-351, 2013. DOI: $10.1016 /$ j.trc.2012.09.012.

[4] T. Liu, "Marine bunker fuel cost management of shipping enterprise", World Shipping, vol. 6, no. 29, pp. 36-37, 2006.

[5] Marine Environment Protection Committee. (2011). Report of The Marine Environment Protection Committee on Its Sixty-Second Session. [Online]. Available: http://www.imo.org/en/KnowledgeCentre/IndexofIMOResolutions/Do cuments/MEPC\%20-

\%20Marine\%20Environment\%20Protection/201\%2862\%29\%20Corr .1.pdf

[6] Y. Yuan, Z. Li, R. Malekian, X. Yan, "Analysis of the operational ship energy efficiency considering navigation environmental impacts", Journal of Marine Engineering \& Technology, vol. 16, no. 3, pp. 150-159, 2017. DOI: 10.1080/20464177.2017.1307716.

[7] International Maritime Organization. (2009). Guidelines for voluntary use of the ship energy efficiency operational indicator (EEOI), London. [Online]. Available: https://gmn.imo.org/wpcontent/uploads/2017/05/Circ-684-EEOI-Guidelines.pdf

[8] D. A. Cooper, "Exhaust emissions from high speed passenger ferries", Atmospheric Environment, vol. 35, no. 24, pp. 4189-4200, 2001. DOI: 10.1016/S1352-2310(01)00192-3.

[9] W. B. Fitzgerald, O. J. A. Howitt, I. J.Smith, "Greenhouse gas emissions from the international maritime transport of New Zealand's imports and exports", Energy Policy, vol. 39, no. 3, pp. 1521-1531, 2011. DOI: 10.1016/j.enpol.2010.12.026.

[10] Peng Yun, Li Xiangda, Wang Wenyuan, Liu Ke, Li Chuan, “A simulation-based research on carbon emission mitigation strategies for green container terminals", Ocean Engineering, vol. 163, pp. 288-298, 2018. DOI: 10.1016/j.oceaneng.2018.05.054.

[11] E. A. Bouman, E. Lindstad, A. I. Rialland, A. H. Stormman, "Stateof-the-art technologies, measures, and potential for reducing GHG emissions from shipping-A review", Transportation Research Part D: Transport \& Environment, vol. 52, pp. 408-421, 2017. DOI: 10.1016/j.trd.2017.03.022.

[12] Sun Xing, Yan Xinping, Wu Bing, Song Xin, "Analysis of the operational energy efficiency for inland river ships", Transportation Research Part D: Transport \& Environment, vol. 22, pp. 34-39, 2013. DOI: $10.1016 /$ j.trd.2013.03.002.

[13] Ching-Chih Chang, Chih-Min Wang, "Evaluating the effects of speed reduce for shipping costs and $\mathrm{CO}_{2}$ emission", Transportation Research Part D: Transport \& Environment, vol. 31, pp. 110-115, 2014. DOI: $10.1016 /$ j.trd.2014.05.020.

[14] J. Corbett, H. Wang, J. Winebrake, "The effectiveness and costs of speed reductions on emission from international shipping", Transportation Research Part D: Transport \& Environment, vol. 14, pp. 593-598, 2009. DOI: 10.1016/j.trd.2009.08.005.

[15] H. Lindstad, B. Asbjornslett, A. Stromman, "Reductions in green house gas emissions and cost by shipping at lower speeds", Energy Policy, vol. 39, no. 6, pp. 3456-3464, 2011. DOI: 10.1016/j.enpol.2011.03.044.

[16] L. P. Ghimire, Y. Kim, "An analysis on barriers to renewable energy development in the context of Nepal using AHP", Renewable Energy, vol. 129, pp. 446-456, 2018. DOI: 10.1016/j.renene.2018.06.011.

[17] Y. Luo, Z. He, C. Wang, "Solar energy utilization technology", Beijing: Chemical industry press, 2006.

[18] P. Jamuna, S. Ramesh, "Experimental validation of impedance source network based active power filter for interconnection of PV system into grid", Journal of Circuits Systems and Computers, vol. 27, no. 14, 2018. DOI: $10.1142 / \mathrm{S} 0218126618502158$.

[19] F. Diab, H. Lan, S. Ali, "Novel comparison study between the hybrid renewable energy systems on land and on ship", Renewable \& Sustainable Energy Reviews, vol. 63, pp. 452-463, 2016. DOI: 10.1016/j.rser.2016.05.053.

[20] N. Ma, "Overview and development prospects on solar photovoltaic", Electrical Technology of Intelligent Buildings, vol. 4, no. 2, pp. 2528, 2011.

[21] X. P. Yan, "Progress review of new energy application in ship", Ship \& Ocean Engineering, vol. 39, no. 6, pp. 111-115, 2011.

[22] Hai Lan, Shuli Wen, Ying-Yi Hong, David C. Yu, Lijun Zhang, "Optimal sizing of hybrid PV/diesel/battery in ship power system", Applied Energy, vol. 158, no. 8, pp. 26-34, 2015. DOI: 10.1016/j.apenergy.2015.08.031

[23] H. Lan, S. Dai, Y. Wen, D. Hong, D. C. Yu, Y. Bai, "Optimal tilt angle of photovoltaic arrays and economic allocation of energy storage system on large oil tanker ship", Energies, vol. 8, no. 10, pp. 11515-11530, 2015. DOI: 10.3390/en81011515.

[24] International Maritime Organization. (2010). Prevention of Air Pollution from Ships, London. [Online]. Available: http://www.imo.org/en/OurWork/Environment/PollutionPrevention/A irPollution/Pages/Air-Pollution.aspx

[25] C. Q. Yuan, Y. Zhang, "Design of grid-connected PV system for large ro-ro ships and its power quality analysis", Navigation of China, vol. 37, no. 3, pp. 21-25, 2014. 